\title{
評価の信頼性
}

\section{Reliability of Evaluation}

谷浩明

HIROAKI TANI, MS, RPT

Department of Physical Therapy, Faculty of Health Sciences, International University of Health and Welfare : 2600-1 Kitakanamaru, Ohtawara-city, Tochigi 324, Japan. TEL +81 287-24-3000

Rigakuryoho Kagaku 12(3): 113-120, 1997. Received Jun. 10, 1997.

ABSTRACT: Objective evaluation is defined as highly reliable evaluation. Even if the measurement method serves the purpose, the possibility exists that "a difference" to be found is covered by large errors. This report reviews the methods for obtaining Intra-rater reliability and Inter-rater reliability using Intraclass correlation coefficient (ICC).

Key words: evaluation, reliability, Intraclass correlation coefficient (ICC)

要旨:客観的な評価とは, 信頼性の高い評価のことを指す。たとえ測定方法が, 測る目的に適した妥当なもの であったとしても, 測定のばらつきが大きいと, 発見したい「ちがい」が, 測定誤差の中に埋もれてしまう可 能性が高くなる。本稿では, 級内相関（ICC：Intraclass Correlation Coefficient）を用いた検者内信頼性, 検者間 信頼性の求めかたを概説する。

キーワード：評価, 信頼性, ICC

国際医療福祉大学 理学療法学科：栃木県大田原市北金丸 2600-1（广 324）TEL 0287-24-3000

受付日 1997年6月10日 


\section{I.はじめに}

臨床においても研究においても測定・評価の客観性と いうことが問題になる。客観的な測定とは「操作的に定 義された手続きに従って測定を行えば，誰でも同じょう に測ることができる」ことである。したがって，測定が 客観的であるということは，信頼性が高いということに 他ならない。こうした意味から，桑原ら 1)は「Reliableの 訳語としては“信頼”よりも“再現”のほうがふさわしい かもしれない」としている。

信頼性の指標として用いられるものにICC（Intraclass correlation coefficient：級内相関）がある。この值の大小 によって, 行われている測定がどの程度の信頼性である か知ることが出来る。本稿では，このICCによる信頼性 係数の求め方を解説する。

\section{II. 検者内信頼性（Intra-rater Reliability）}

ここでは, 評価する側の検者間の違いの要素を考慮し ない検者内信頼性（Intra-rater reliability）について考えて みる。表 1 はその例である。1 人の検者が, n 人の患者に 対して $\mathrm{k}$ 回繰り返しの測定を行っている。このときの測 定值 X は次のように表すことが出来る。

$$
\begin{aligned}
\mathrm{X}_{\mathrm{ij}}= & \pi_{\mathrm{i}}+\mathrm{e}_{\mathrm{ij}} \ldots \ldots \ldots \ldots \ldots \\
& \mathrm{X}_{\mathrm{ij}} \text { : 測定值 } \\
& \pi_{\mathrm{i}} \text { : 測定される } \mathrm{i} \text { 人目の患者の真の值 } \\
& \mathrm{e}_{\mathrm{ij}} \text { : 測定誤差 }
\end{aligned}
$$

表 2 ばらつきの内訳

a)

\begin{tabular}{|llll|}
\hline 10 & 10 & 10 & 10 \\
10 & 10 & 10 & 10 \\
10 & 10 & 10 & 10 \\
\hline
\end{tabular}

このとき, 測定值 $\mathrm{X}_{\mathrm{ij}}$ のばらつきである分散 $\sigma^{2}{ }_{\mathrm{x}}$ は, 次の ように表される。

$$
\sigma_{\mathrm{x}}^{2}=\sigma_{\mathrm{n}}^{2}+\sigma_{\mathrm{e}}^{2}
$$

ここで, 式(1)においてすべての患者の真の值が同じ $\left(\pi_{1}=\pi_{2}=\cdots=\pi_{\mathrm{i}}=\cdots=\pi_{\mathrm{n}}\right)$ で，かつ測定誤差が全くな い $\left(\mathrm{e}_{\mathrm{ij}}=0\right)$ と仮定すると, 当然のことながら測定值 $X_{\mathrm{ij}}$

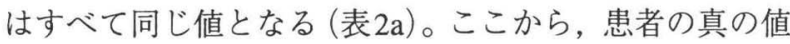
は同じ $(\pi=10)$ で測定誤差のみ存在する状態 (表 $2 b)$ と 患者の真の値は異なる $\left(\pi_{1}=5, \pi_{2}=10, \pi_{3}=15\right)$ が測定誤 差が存在しない状態（表 2c）を考えると，実際の測定結 果である表 $2 \mathrm{~d}$ の測定値のばらつき $\left(\sigma_{\mathrm{x}}^{2}\right)$ が，患者の真の 値のばらつき $\left(\sigma^{2}\right)$ と測定誤差のばらつき $\left(\sigma_{\mathrm{e}}^{2}\right)$ をあわ せたものであることは容易に理解できるであろう。測定 の信頼性とは，測定値のばらつき $\left(\sigma^{2} x\right)$ のうち，真の值 のばらつき $\left(\sigma^{2}\right)$ がどの程度の割合であるかということ

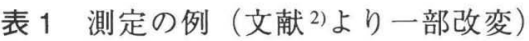

\begin{tabular}{ccccccccc}
\hline & 1 & 2 & $\cdots$ & $\mathrm{j}$ & $\cdots$ & $\mathrm{k}$ & Total & Mean \\
\hline 1 & $\mathrm{X}_{11}$ & $\mathrm{X}_{12}$ & & $\mathrm{X}_{1 \mathrm{j}}$ & & $\mathrm{X}_{1 \mathrm{k}}$ & $\mathrm{P}_{1}$ & $\overline{\mathrm{P}_{1}}$ \\
2 & $\mathrm{X}_{21}$ & $\mathrm{X}_{22}$ & & $\mathrm{X}_{2 \mathrm{j}}$ & & $\mathrm{X}_{2 \mathrm{k}}$ & $\mathrm{P}_{2}$ & $\overline{\mathrm{P}_{2}}$ \\
$\cdot$ & $\cdot$ & $\cdot$ & $\cdot$ & $\cdot$ & $\cdot$ & $\cdot$ & $\cdot$ & $\cdot$ \\
$\cdot$ & $\cdot$ & $\cdot$ & $\cdot$ & $\cdot$ & $\cdot$ & $\cdot$ & $\cdot$ & $\cdot$ \\
$\cdot$ & $\cdot$ & $\cdot$ & $\cdot$ & $\cdot$ & $\cdot$ & $\cdot$ & $\cdot$ & $\cdot$ \\
$\mathrm{i}$ & $\mathrm{X}_{\mathrm{i} 1}$ & $\mathrm{X}_{\mathrm{i} 2}$ & & $\mathrm{X}_{\mathrm{ij}}$ & & $\mathrm{X}_{\mathrm{ik}}$ & $\mathrm{P}_{\mathrm{i}}$ & $\overline{\mathrm{P}_{\mathrm{i}}}$ \\
$\cdot$ & $\cdot$ & $\cdot$ & $\cdot$ & $\cdot$ & $\cdot$ & $\cdot$ & $\cdot$ & $\cdot$ \\
$\cdot$ & $\cdot$ & $\cdot$ & $\cdot$ & $\cdot$ & $\cdot$ & $\cdot$ & $\cdot$ & $\cdot$ \\
$\cdot$ & $\cdot$ & $\cdot$ & $\cdot$ & $\cdot$ & $\cdot$ & $\cdot$ & $\cdot$ & $\cdot$ \\
$\mathrm{n}$ & $\mathrm{X}_{\mathrm{n} 1}$ & $\mathrm{X}_{\mathrm{n} 2}$ & & $\mathrm{X}_{\mathrm{nj}}$ & & $\mathrm{X}_{\mathrm{nk}}$ & $\mathrm{P}_{\mathrm{n}}$ & $\overline{\mathrm{P}_{\mathrm{n}}}$ \\
\hline Total & $\mathrm{T}_{1}$ & $\mathrm{~T}_{2}$ & & $\mathrm{~T}_{\mathrm{j}}$ & & $\mathrm{T}_{\mathrm{k}}$ & $\mathrm{G}$ & $\overline{\mathrm{G}}$ \\
\hline
\end{tabular}

c)

\begin{tabular}{|cccc|}
\hline 5 & 5 & 5 & 5 \\
10 & 10 & 10 & 10 \\
15 & 15 & 15 & 15 \\
\hline
\end{tabular}

b)

\begin{tabular}{|cccc|}
\hline 11 & 9 & 10 & 10 \\
11 & 10 & 9 & 10 \\
9 & 10 & 11 & 10 \\
\hline
\end{tabular}

d)

$\begin{array}{cccc}6 & 4 & 5 & 5 \\ 11 & 10 & 9 & 10 \\ 14 & 15 & 16 & 15\end{array}$


であり, 次の式のように表される。

$$
\mathrm{r}=\frac{\sigma_{\mathrm{n}}^{2}}{\sigma_{\mathrm{x}}^{2}+\sigma_{\mathrm{e}}^{2}}
$$

表 1 中の $\mathrm{P}_{\mathrm{i}}$ は $\mathrm{i}$ 番目の患者の測定值 $\mathrm{k}$ 回分の総計で, $\overline{\mathrm{P}}_{\mathrm{i}}$ は $\mathrm{i}$ 番目の患者の測定値の平均である。 $\overline{\mathrm{G}}$ は全測定值の総 計, $\overline{\mathrm{G}}$ は全測定值の平均である。このとき, 全体のばら つき具合の総和を示す全平方和 $\left(\mathrm{SS}_{\text {total }}\right)$ は各測定值から 総平均を引いて 2 乗したものの総計であるから

$$
\mathrm{SS}_{\text {total }}=\sum_{\mathrm{i}=1}^{\mathrm{n}} \sum_{j=1}^{\mathrm{k}}\left(\mathrm{X}_{\mathrm{ij}}-\overline{\mathrm{G}}\right)^{2}
$$

この全平方和は, 患者間のばらつきの総和 $\left(\mathrm{SS}_{\mathrm{b}} \cdot\right.$ people $)$ と 患者内のばらつきの総和 $\left(\mathrm{SS}_{\mathrm{w}} \cdot\right.$ people $)$ からなる (図 1$)$ 。 まず，患者間のばらつきの総和 $\left(\mathrm{SS}_{\mathrm{b} \cdot \text { people }}\right)$ は, 各患者の 測定值の平均と総平均との差を 2 乗して患者の人数分た しあわせたものに繰り返し分を乗じたものとなる。

$$
\mathrm{SS}_{\mathrm{b}} \cdot \text { people }=\mathrm{k} \sum_{\mathrm{i}=1}^{\mathrm{n}}\left(\overline{\mathrm{P}}_{\mathrm{i}}-\overline{\mathrm{G}}\right)^{2}
$$

いわゆる測定誤差にあたる患者内のばらつきの総和 $\left(\mathrm{SS}_{\mathrm{w}} \cdot\right.$ people $)$ は, 各測定值と患者の測定值の平均との差分 の 2 乗を患者の人数分だけ足したものになる。

$$
\mathrm{SS}_{\mathrm{b}} \cdot \text { people }=\sum_{\mathrm{i}=1 \mathrm{j}=1}^{\mathrm{n}} \sum_{\mathrm{l}}^{\mathrm{k}}\left(\mathrm{X}_{\mathrm{ij}}-\overline{\mathrm{P}}_{\mathrm{i}}\right)^{2} .
$$

それぞれの平方和の持つ自由度は図 1 に示すとおりなの で, 各不偏分散 (MS) は次のように, また, 分散分析表 は表 3 に示すとおりとなる。

$\mathrm{MS}_{\mathrm{b}} \cdot$ people $=\frac{\mathrm{SS}_{\mathrm{b}} \cdot \text { people }}{\mathrm{n}-1}$

Partition of the total variation

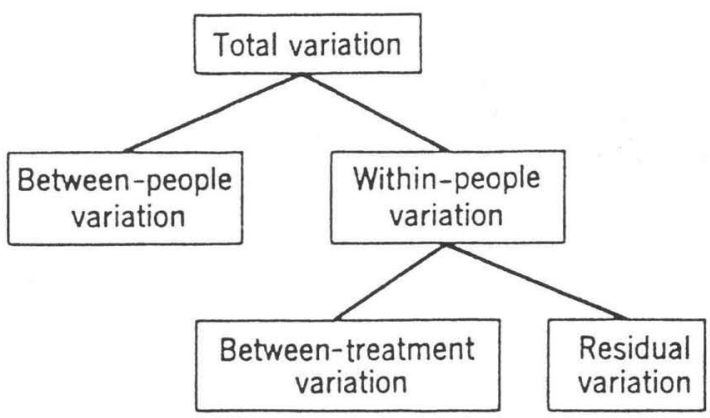

$$
\mathrm{MS}_{\mathrm{w}} \cdot \text { people }=\frac{\mathrm{SS}_{\mathrm{w}} \cdot \text { people }}{\mathrm{n}(\mathrm{k}-1)}
$$

この分散分析表の期待値から, 式(3)の $\sigma_{\mathrm{e}}^{2}$ の推定値は $\mathrm{MS}_{\mathrm{w}} \cdot$ people そのものであり, このことから

$$
\mathrm{SS}_{\mathrm{b}} \cdot \text { people }=\sigma_{\mathrm{e}}^{2}+\mathrm{k}^{2}{ }_{\mathrm{n}}=\mathrm{MS}_{\mathrm{w}} \cdot \text { people }+\mathrm{k} \sigma_{\mathrm{n}}^{2}
$$

したがって式(3)の $\sigma^{2}$ の推定值は

$$
\sigma_{n}^{2}=\frac{S S_{b} \cdot \text { people }}{-M S_{w} \cdot \text { people }} \text {. }
$$

となり, 式(3)のrは次のように推定することが出来る。

$$
\mathrm{r}=\frac{\mathrm{SS}_{\mathrm{b}} \cdot \text { people }}{-\mathrm{MS}_{\mathrm{w}} \cdot \text { people }}
$$

分散分析表を作り，この式を計算すれば，検者内信頼 性（Intra-rater Reliability）を求めることが出来る。信頼性 係数 $\mathrm{r}$ のおおまかな評価基準は表 4 に示す。

\section{表 3 ANOVA 表 (1)}

\begin{tabular}{llc}
\hline 変動因子 & 不偏分散 & 不偏分散の期待値 \\
\hline 患者間 & $\mathrm{MS}_{\mathrm{b}} \cdot$ people & $\sigma^{2} \mathrm{e}+\mathrm{k \sigma}^{2} \pi$ \\
患者内 $(=$ 測定誤差 $)$ & $\mathrm{MS} \mathrm{w}_{\mathrm{w}} \cdot$ people & $\sigma^{2}{ }_{\mathrm{e}}$ \\
\hline
\end{tabular}

表 4 信頼性係数 $\mathrm{r}$ の大まかな基準 ${ }^{1)}$

\begin{tabular}{lcc}
\hline $0.9-$ & great & 優秀 \\
$0.8-$ & good & 良好 \\
$0.7-$ & OK (fair) & 普通 \\
$0.6-$ & possible & 可能 \\
-0.6 & re-work & 要再考 \\
\hline
\end{tabular}

Partition of the degrees of freedom

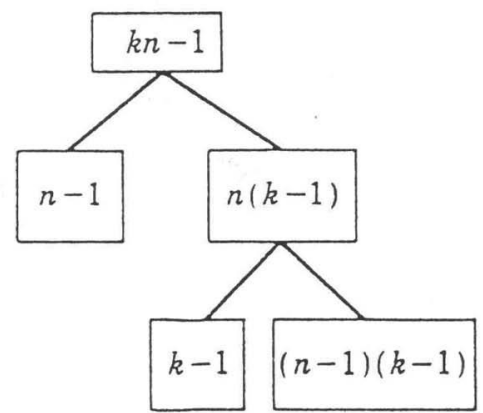

図1 ばらつきの分解と自由度 ${ }^{2)}$ 
こうして求められた信頼性は, 1 回の測定についての 信頼性である。したがって, 測定値に, 繰り返し測定し た平均値を用いれば, この信頼性を向上させることがで きる。これは, いわゆる信頼性を求めることを主目的と した研究だけではなく, パイロット・スタディの測定結 果から推定された信頼性係数をもとに, 本実験の測定で の繰り返し回数を決定するといった用途にも有効であ る。

式(11)によって, すでに1回測定の信頼性 $\mathrm{r}$ (以下, $\mathrm{r}_{1}$ と する)がわかっている場合, $\mathrm{k}$ 回繰り返し測定の平均値の 信頼性 $\mathrm{r}_{\mathrm{k}}$ は以下の式で求められる。

$$
\mathrm{r}_{\mathrm{k}}=\frac{\mathrm{kr}_{1}}{1+(\mathrm{k}-1) \mathrm{r}_{1}}
$$

1 回測定の信頼性 $\mathbf{r}_{1}$ を求める前の段階であれば， $\sigma^{2}$ を $\sigma_{\mathrm{e}}^{2}$ で除した $\theta$ の推定值を計算すると便利である。

$$
\theta=\frac{\sigma_{\mathrm{n}}^{2}}{\sigma_{\mathrm{n}}^{2}}=\frac{\mathrm{MS}_{\mathrm{b}} \cdot \text { people }}{-\mathrm{MS}_{\mathrm{w}} \cdot \text { people }}
$$

この值を以下の(14)式に代入すれば任意の $\mathrm{r}_{\mathrm{k}}$ を求める ことができる。

$$
\mathrm{r}_{\mathrm{k}}=\frac{\mathrm{k} \theta}{1+\mathrm{k} \theta}
$$

このようにして推定される検者内信頼性とは, 当然, 一人の検者についての信頼性であるので, 適用は, その
検者と他の検者では違いがないと確信できる場合, もし くはその研究において測定を行うのはその検者一人だけ である場合に限られる。

以下に具体的な数值を用いた手順を示す。

【例 1】

頸椎撮影した MRIの C4 - 5 間の椎間孔の面積を測定 するため，その画像をスキャナを用いてコンピュータに 取り込んだ。検者はコンピュータ画面上の椎間孔の輪郭 をマウスでなぞることによって決定，この輪郭をもとに ソフトウェア上で面積計算が行われた。1人の検者が7人 の被験者について各 5 回の測定を行った結果を表 5 に示 す。このときの検者内信頼性を求める。

$<$ 手順 $>$

測定繰り返し数 $\mathrm{k}=5$

被験者数 $\mathrm{n}=7$

(1) 2 乗表を作る（表 6)

(2)次の値を求める

(1) $\frac{\mathrm{G}^{2}}{\mathrm{kn}}=\frac{(34)^{2}}{35}=33.03$

(2) $\sum_{i=1}^{n} \sum_{j=1}^{k}\left(X_{i j}\right)^{2}=35.40$

\begin{tabular}{|c|c|c|c|c|c|c|c|c|}
\hline & 測定 1 & 測定 2 & 測定 3 & 測定 4 & 測定 5 & $P_{i}$ & $\mathrm{P}_{\mathrm{i}}^{2}$ & $\sum_{i=1}^{n} P_{i}^{2}$ \\
\hline 患者 1 & 0.77 & 0.78 & 0.78 & 0.77 & 0.75 & 3.85 & & \\
\hline 患者 2 & 1.10 & 1.11 & 1.15 & 1.08 & 1.10 & 5.54 & 30.69 & \\
\hline 患者 3 & 1.37 & 1.36 & 1.34 & 1.34 & 1.34 & 6.75 & 45.56 & \\
\hline 患者 4 & 1.05 & 1.04 & 1.06 & 1.07 & 1.08 & 5.30 & 28.09 & \\
\hline 患者 5 & 0.90 & 0.91 & 0.94 & 0.91 & 0.95 & 4.61 & 21.25 & \\
\hline 患者 6 & 1.14 & 1.13 & 1.10 & 1.11 & 1.06 & 5.54 & 30.69 & \\
\hline 患者 7 & 0.47 & 0.47 & 0.51 & 0.48 & 0.48 & 2.41 & $5.8 y$ & \\
\hline $\mathrm{T}_{\mathrm{j}}$ & 6.80 & 6.80 & 6.88 & 6.76 & 6.76 & 4 & & 176.92 \\
\hline $\mathrm{T}_{\mathrm{j}}^{2}$ & 46.24 & 46.24 & 47.33 & 45.70 & 45.70 & & & \\
\hline$\sum_{j=1}^{k} T_{j}^{2}$ & & & & & & & & $G$ \\
\hline
\end{tabular}

(3) $\frac{\Sigma \mathrm{T}^{2} \mathrm{j}}{\mathrm{n}}=\frac{231.21}{7}=33.03$

表 5 面積計算の測定結果 
(4) $\frac{\Sigma \mathrm{P}_{\mathrm{i}}}{\mathrm{k}}=\frac{176.92}{5}=35.38$

(3)各平方和を求める

$\begin{array}{lll}\mathrm{SS}_{\mathrm{b}} \cdot \text { people } & =(4)-(1) & =2.3551 \\ \mathrm{SS}_{\mathrm{w}} \cdot \text { people } & =(2)-(4) & =0.0119 \\ \mathrm{SS}_{\mathrm{b}} \cdot \text { judges } & =(3)-(1) & =0.0014 \\ \mathrm{SS}_{\text {res }} & =(2)-(3)-(4)+(1) & =0.0105 \\ \mathrm{SS}_{\text {total }} & =(2)-(1) & =2.3607\end{array}$

(4)分散分析表を作る (表 7)

(5) $\theta$ の推定值を求める。

$\theta=\frac{0.93252-0.00043}{5 \times 0.00043}=184.20447$

(6) 1 回測定の信頼性係数 $\mathbf{r}_{1}$ を求める

$r_{1}=\frac{184.20447}{1+184.20447}=0.99460$

(7) 3 回測定の信頼性係数 $\mathrm{r}_{5}$ を求める

$r_{3}=\frac{3 \times 184.20447}{1+3 \times 184.20447}=0.99819$

表 6 二乗表 (1)

\begin{tabular}{lcccccc}
\hline & 測定 1 & 測定 2 & 測定 3 & 測定 4 & 測定 5 & Total \\
\hline 患者 1 & 0.59 & 0.61 & 0.61 & 0.59 & 0.56 & 2.97 \\
患者 2 & 1.21 & 1.23 & 1.32 & 1.17 & 1.21 & 6.14 \\
患者 3 & 1.88 & 1.85 & 1.80 & 1.80 & 1.80 & 9.11 \\
患者 4 & 1.10 & 1.08 & 1.12 & 1.14 & 1.17 & 5.62 \\
患者 5 & 0.81 & 0.83 & 0.88 & 0.83 & 0.90 & 4.25 \\
患者 6 & 1.30 & 1.28 & 1.21 & 1.23 & 1.12 & 6.14 \\
患者7 & 0.22 & 0.22 & 0.26 & 0.23 & 0.23 & 1.16 \\
\hline Total & 7.11 & 7.10 & 7.20 & 6.99 & 6.99 & 35.40 \\
\hline
\end{tabular}

表 7 ANOVA 表 (2)

\begin{tabular}{lccc}
\hline 変動因子 & 平方和 & 自由度 & 不偏分散の期待値 \\
\hline 患者間 & 2.3551 & 6 & 0.39252 \\
患者内 & 0.0119 & 28 & 0.00043 \\
$\quad$ 反復測定間 & 0.0014 & 4 & 0.00034 \\
$\quad$ 残差 & 0.0105 & 24 & 0.00044 \\
\hline
\end{tabular}

\section{III. 検者間信頼性（Inter-rater Reliability）}

検者間信頼性は複数の患者を複数の測定者が評価する 際の測定者同士の信頼性のことであり, ランダム効果と, 固定効果に分けられる。検者内信頼性がくりかえしのあ る一元配置の形をとるのに対し，これら検者間信頼性は 患者, 測定者それぞれを因子とする二元配置の形をとる。

(1)ランダム効果 (Random effects)

例えば，ROM測定の信頼性を評価する場合，その測定 に参加したk人というのが, 臨床で働く $\mathrm{PT}$ という集団か ら無作為抽出されたものであるとし, 任意の測定者の検 者間信頼性を考えるならば，これはランダム効果という ことになる。

ランダム効果による検者間信頼性は，一般に $\operatorname{ICC}(2,1)$ で表される。

さきの検者内信頼性における繰り返し測定の部分（表 1 における各列）を検者に置き換えると, $\mathrm{k}$ 人の検者が $\mathrm{n}$ 人の患者を測定した二元配置（繰り返しなし）の結果と なる。検者による影響を考慮すると測定值のモデルは以 下のように考えられる。

$$
\mathrm{X}_{\mathrm{ij}}=\pi_{\mathrm{i}}+\alpha_{\mathrm{j}}+\mathrm{e}_{\mathrm{ij}} \text {. }
$$

$\mathrm{X}_{\mathrm{ij}}$ ：測定値

$\pi_{\mathrm{i}} \quad$ : 測定される $\mathrm{i}$ 人目の患者の真の値

$\alpha_{\mathrm{j}}: \mathrm{j}$ 人目の検者による効果

$\mathrm{e}_{\mathrm{ij}}$ : 測定誤差

分散の構造は

$$
\sigma^{2}{ }_{\mathrm{x}}=\sigma_{\mathrm{n}}^{2}+\sigma_{\mathrm{a}}^{2}+\sigma_{\mathrm{e}}^{2}
$$

その信頼性は

$$
\mathrm{R}=\frac{\sigma_{\mathrm{n}}^{2}}{\sigma_{\mathrm{n}}^{2}+\sigma_{\mathrm{a}}^{2}+\sigma_{\mathrm{e}}^{2}}
$$

で表される。検者間のばらつきの平方和 $\mathrm{SS}_{\mathrm{w} \text {.people }}$ を検者 による効果分 $\mathrm{SS}_{\text {raters }}$ (検者内信頼性における $\mathrm{SS}_{\text {judges }}$ に同 じ）と残差分 $\mathrm{SS}_{\mathrm{res}}$ に分離した際の分散分析表を表 8 に示 す。不偏分散の期待值から式(16)の右辺の各分散の推定 值は次のように表される。

$$
\sigma^{2}=M_{\text {res }}
$$

\begin{tabular}{|c|c|c|c|c|}
\hline 変動因子 & 平方和 & 自由度 & 不偏分散 & 不偏分散の期待値 \\
\hline 患者間 & $\mathrm{SS}_{\mathrm{b}} \cdot$ people & $n-1$ & $\mathrm{MS}_{\mathrm{b}} \cdot$ people & $\sigma_{\mathrm{e}}^{2}+\mathrm{k} \sigma_{\pi}^{2}$ \\
\hline 検者間 & $S S_{\text {raters }}$ & $\mathrm{k}-1$ & $\mathrm{MS}_{\text {raters }}$ & $\sigma_{e}^{2}+n \sigma_{\alpha}^{2}$ \\
\hline 誤差 & $\mathrm{SS}_{\text {res }}$ & $(n-1)(k-1)$ & $\mathrm{MS}_{\text {res }}$ & $\sigma_{\mathrm{e}}^{2}$ \\
\hline
\end{tabular}

表 8 ANOVA表 -(3) 


$$
\begin{aligned}
\sigma^{2}{ }_{\mathrm{n}} & =\frac{\mathrm{MS}_{\mathrm{b}} \cdot \text { people }}{\mathrm{k}} \mathrm{MS}_{\mathrm{res}} \\
\sigma_{\mathrm{a}}^{2} & =\frac{\mathrm{MS}_{\mathrm{raters}}-\mathrm{MS}_{\mathrm{res}}}{\mathrm{n}}
\end{aligned}
$$

これを式(17)の分散の推定值として代入してやるとラン ダム効果による検者間信頼性, $\operatorname{ICC}(2,1)$ が求まる。

$\operatorname{ICC}(2,1)$

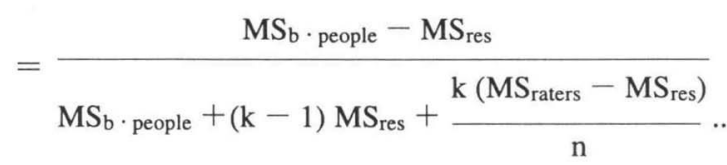

以下に具体例と手順を示す。

【例 2】

例 1 の椎間孔面積の測定を, 3 人の検者が7人の患者に 関して行った結果を表 9 に示す。このときのランダム効 果による検者間信頼性を計算する。

$<$ 手順 $>$

（1）乗表を作る（表 10）

(2)次の值を求める

\begin{tabular}{|c|c|c|c|c|c|c|}
\hline & 検者 1 & 検者 2 & 検者 3 & $\mathrm{P}_{\mathrm{i}}$ & $\mathrm{P}_{\mathrm{i}}^{2}$ & $\sum_{i=1}^{n} P_{i}^{2}$ \\
\hline 患者 1 & 0.80 & 0.51 & 0.77 & 2.08 & 4.33 & \\
\hline 患者 2 & 0.82 & 0.82 & 1.11 & 2.75 & 7.55 & \\
\hline 患者 3 & 1.39 & 0.94 & 1.35 & 3.68 & 13.54 & \\
\hline 患者 4 & 1.04 & 0.84 & 1.06 & 2.94 & 8.64 & \\
\hline 患者 5 & 0.97 & 0.56 & 0.92 & 2.46 & 6.04 & \\
\hline 患者 6 & 1.37 & 1.11 & 1.11 & 3.59 & 12.87 & \\
\hline 患者 7 & 0.60 & 0.39 & 0.48 & 1.48 & 2.18 & \\
\hline $\mathrm{T}_{\mathrm{j}}$ & 6.99 & 5.18 & 6.80 & 18.97 & & 55.16 \\
\hline $\mathrm{T}_{\mathrm{j}}^{2}$ & 48.89 & 26.81 & 46.24 & & & \\
\hline$\sum_{j=1}^{k} T_{j}^{2}$ & & & & 121.94 & & \\
\hline
\end{tabular}

$$
\begin{aligned}
& \text { (1) } \frac{\mathrm{G}^{2}}{\mathrm{kn}}=\frac{(18.97)^{2}}{21}=17.136 \\
& \text { (2) } \sum_{\mathrm{i}=1}^{\mathrm{n}} \sum_{j=1}^{\mathrm{k}}\left(\mathrm{X}_{\mathrm{ij}}\right)^{2}=18.816
\end{aligned}
$$

表 9 面積計算の結果（2）
(3) $\frac{\sum T_{2 j}}{n}=\frac{121.94}{7}=17.420$
(4) $\frac{\sum \mathrm{P}_{\mathrm{i}}}{\mathrm{k}}=\frac{55.16}{3}=18.386$

(3)各平方和を求める

$$
\begin{aligned}
& \mathrm{SS}_{\mathrm{b}} \cdot \text { people }=(4)-(1) \quad=1.250 \\
& \mathrm{SS}_{\mathrm{w}} \cdot \text { people }=(2)-(4) \quad=0.430 \\
& \mathrm{SS}_{\mathrm{b} \cdot \text { raters }}=(3)-(1) \quad=0.284 \\
& \mathrm{SS}_{\text {res }}=(2)-(3)-(4)+(1)=0.146 \\
& \mathrm{SS}_{\text {total }}=(2)-(1) \quad=1.680
\end{aligned}
$$

(4)分散分析表を作る（表 11）

(5) ICC $(2,1)$ を求める。 $\operatorname{ICC}(2,1)$

$$
\begin{aligned}
& =\frac{0.208-0.012}{0.208+(3-1) \times 0.012+\frac{3 \times(0.142-0.012)}{7}} \\
& =0.680
\end{aligned}
$$

\section{(2)固定効果 (Fixed effects)}

ランダム効果による信頼性 $\operatorname{ICC}(2,1)$ が任意の検者につ いてという一般化したものであるのに対し, 固定効果に よる $\operatorname{ICC}(3,1)$ は, 測定に参加した検者群そのものが対象 となる。

表 10 二乗表 (1)

\begin{tabular}{lrrrr}
\hline & 検者 1 & 検者 2 & 検者 3 & \multicolumn{2}{l}{ Total } \\
\hline 患者 1 & 0.63 & 0.26 & 0.59 & 1.49 \\
患者 2 & 0.67 & 0.68 & 1.23 & 2.57 \\
患者 3 & 1.94 & 0.88 & 1.82 & 4.64 \\
患者 4 & 1.08 & 0.71 & 1.12 & 2.91 \\
患者 5 & 0.95 & 0.32 & 0.85 & 2.11 \\
患者6 & 1.89 & 1.22 & 1.23 & 4.34 \\
患者7 & 0.36 & 0.16 & 0.23 & 0.75 \\
\hline Total & 7.52 & 4.22 & 7.08 & 18.82 \\
\hline
\end{tabular}

表 11 ANOVA 表（4）

\begin{tabular}{lccc}
\hline 変動因子 & 平方和 & 自由度 & 不偏分散 \\
\hline 患者間 & 1.25 & 6 & 0.208 \\
患者内 & 0.284 & 2 & 0.142 \\
残 差 & 0.146 & 12 & 0.012 \\
\hline
\end{tabular}


したがって【例2】で求めた $\operatorname{ICC}(2,1)$ は,「マウスを使っ て画像診断を行う人」という母集団を想定していること になり，その画像診断の方法を一般化する際の検者間信 頼性ということができる。ここでの信頼性を高くするに は式(17)を見ても分かるように，測定誤差を小さくする か, 検者による効果のばらつきを小さくすることで可能 となる。検者による効果のばらつきが小さくなるとは, 検者間で值の一致 (agreement) が見られるということに 他ならない。検者群を固定して考えた場合, 研究の目的 によっては值の相関 (consistency) を問題にすることは あっても, 一致 (agreement) まで問題にしない場合もあ る。

例えば 2 人の検者が 5 人の患者を測定する場合を考え てみる（図2）。検者 $\mathrm{A}$ と B の間で, 測定值そのものの一 致は見られないが,「患者 2 は高く, 患者 5 は低い測定值 を示す」という傾向は一致しており，その点では再現性 が高いといえる。このように, agreementが低くても consistency が高いかどうかを評価することで目的が達せ られる場合には, 固定効果の $\operatorname{ICC}(3,1)$ を用いる。式にも どって考えてみよう。agreementを無視するということ は, 式(15)中の $\alpha_{\mathrm{j}}$ の項を考慮しなくてよいということに なる。したがって, 分散分析によって検者による効果を 誤差分散から分離するところまでは同じだが, 最後の信 頼性係数を求める式は, 検者による分散の項を含まない で次のようになる。

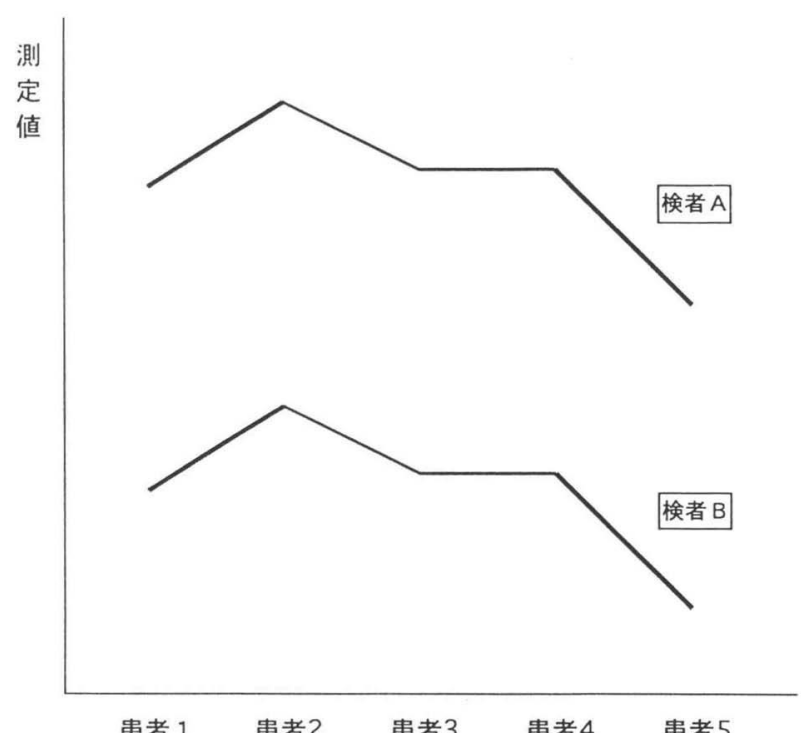

患者 1 患者2 患者3 患者4 患者5

$$
R=\frac{\sigma_{n}^{2}}{\sigma_{n}^{2}+\sigma_{e}^{2}}
$$

したがって ICC(3,1)は式(18),(19)を用いて

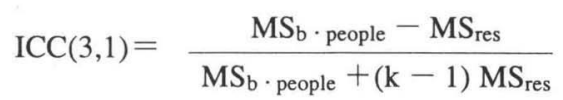

となる。

【例 2】のデータを用いて $\operatorname{ICC}(3,1)$ を求めると

$$
\operatorname{ICC}(3,1)=\frac{0.208-0.012}{0.208+(3-1) \times 0.012}=0.845
$$

となり，検者による効果を除いた分だけ ICC $(2,1) の 0.68$ より高い值となることがわかる。

これらの検者間信頼性も, 検者内信頼性の式(12)で, $\mathrm{k}$ 回繰り返し測定の平均值を用いたときの信頼性係数 ICC $(2, \mathrm{k})$, あるいは ICC $(3, \mathrm{k})$ を求めることができる。上記【例 2】のデータの場合も，4回測定の平均值をとると以下の ように信頼性の向上がみられる。

$$
\begin{aligned}
& \operatorname{ICC}(2,4)=\frac{4 \times 0.680}{1+(4-1) \times 0.680}=0.895 . \\
& \operatorname{ICC}(3,4)=\frac{4 \times 0.845}{1+(4-1) \times 0.845}=0.956 .
\end{aligned}
$$

\section{VI. おわりに}

我々が信頼性にこだわらなければならないのは，測定 にはばらつきがつきものだからである。このばらつき をなくせない以上，うまくコントロールしてその中から 意味のあるものを得なければならず，信頼性の評価は， 意味あるものを埋もれさせないためのひとつの道具とい うことができる。ただ，先述したようにどのICCを選択 するのかといったことは, 研究者に委的られており，そ の選択にあたっては，自らがなにを目的にどのようなデ ザインで実験（測定）を行おうとしているのかを明確に しなければならない。

また, こうして求めた信頼性がいくら高くても, その こと自体は評価の妥当性とはまったく関係ないことも気 にとめておくべきだろう。

図2 Consistencyの一致 


\section{引用・参考文献}

1) 桑原洋一・他: 検者内および検者間の Reliability（再現性, 信 頼性) の検討. 呼と循, 41(10): 945-952, 1993.

2) Winer BJ: Statistical Principles In Experimental Design, 2nd ed., McGraw-Hill, New York, 1971.

3) Shrout PE, et al.: Intraclass Correlations : Uses in Assessing Rater
Reliability. Psychological Bulletin, 86: 420-428, 1979.

4) Bartko JJ : The Intraclass Correlation Coefficient as a Measure of Reliability. Psychological Reports, 19: 3-11, 1966.

5) Eliasziw M, et al.: Statistical Methodology for the Concurrent Assessment of Intrarater and Intrarater Reliability: Using Goniometric Measurements as an Example. Physical Therapy, 74: 777-778, 1994. 